\title{
PHYTOCHEMICAL SCREENING, ANALGESIC ACTIVITY, AND ANTIDEPRESSANT ACTIVITY OF THE METHANOL EXTRACT OF GAULTHERIA FRAGRANTISSIMA WALL. IN WISTAR RATS
}

\author{
FREDDY TEILANG NONGKHLAW*, MALSAWMTLUANGI C, PHAIBIANG LAPASAM, ANDREW LALTHASANGA
}

Department of Pharmacy, Regional Institute of Paramedical and Nursing Sciences, Aizawl, Mizoram, India. Email: freddy.teilang@gmail.com

Received: 10 August 2020, Revised and Accepted: 11 September 2020

\section{ABSTRACT}

Objective: The present study was undertaken to screen the analgesic and the antidepressant activity of Gaultheria fragrantissima Wall. an ethnomedicinal plant of Meghalaya, India.

Methods: In this study, the analgesic effect was induced by hot plate method and tail immersion test. The analgesic effect of two doses of the methanolic extract of Gaultheria fragrantissima Wall. was tested and diclofenac was used as a standard drug. The antidepressant activity was brought about by force swimming test and tail suspension test. The antidepressant effect of two doses of the methanolic extract of $G$. fragrantissima Linn. was tested and imipramine was used as a standard drug. The statistical analysis was carried out by one-way analysis of variance (ANOVA) followed by Tukey-Kramer multiple comparison tests using GraphPad InStat 3.0 software.

Results: The analgesic study shows that the plant extract at two different doses (200 mg/kg and $400 \mathrm{mg} / \mathrm{kg})$ possesses significant analgesic activity $(\mathrm{p}<0.01)$, whereby the two different doses of the plant extract showed a significant increase in the latency time were obtained at 120 min in hot plate method and increase in the latency time were obtained at $90 \mathrm{~min}$ in the tail immersion method, respectively. The antidepressant study shows us that the methanolic extract at 200 and $400 \mathrm{mg} / \mathrm{kg}$ produced significant reduction $(\mathrm{p}<0.001)$ in the immobility period when compared with that of control group animals in both the tests.

Conclusion: The result of the study shows that the methanolic bark extract of G. fragrantissima Wall. possesses analgesic activity and antidepressant activity.

Keywords: Gaultheria fragrantissima, Analgesic, Antidepressant, Diclofenac, Latency

(C) 2020 The Authors. Published by Innovare Academic Sciences Pvt Ltd. This is an open access article under the CC BY license (http://creativecommons. org/licenses/by/4. 0/) DOI: http://dx.doi.org/10.22159/ajpcr.2020.v13i11.39353

\section{INTRODUCTION}

The most ancient form of health care in the world is usually used in the prevention, and treatment of physical and mental illnesses is traditional medicine. Many societies developed through history various useful healing methods to fight against a variety of health and life-threatening ailments [1]. The foundations of traditional systems of medicine through ages of years have been formed indefinitely from the plants. The plants thus remain to offer mankind with new medicinal options [2]. Different forms of traditional medicine if applied successfully will assist in the development of new drugs entities, producing abundant beneficial advantages such as significantly lower cost of drugs [3]. There is a humungous prospect for future findings from plants and various natural products which offers a huge boost in procuring useful data about novel chemical structures and new features of the types of activities related to the development of drugs [4].

The international association for the study of pain defines pain as a bad sensory and emotional experience related to tissue injury [5]. Pain is a protective mechanism. It occurs when tissues are damaged and there is a natural reaction from the individual to remove pain stimulus. The pain receptors are free nerve endings [6]. The therapeutic actions of nonsteroidal anti-inflammatory drugs (NSAIDs) are manifested by their ability to block certain prostaglandins (PGs) synthesis through the cyclooxygenase enzymes (COX-1 and COX-2) inhibition [7]. NSAIDs are used as pain reducers, however, they cause adverse effects such as acidity, gastric lesions, and the use of these drugs has not been successful in all the cases. Hence, a wide range of research is underway to find alternative options for NSAIDs [8].
One of the most well-acclaimed mental disorders is depression which manifests itself through symptoms mentally and the psychological state of mind of a person. A person suffering from depression is indifferent, the energy level is down, thoughts and activity are slowed down, and is accompanied with a mixed feeling of sadness and dejection [9]. Antidepressants are the drugs that act in helping in reducing the symptoms of depressive disorders by transforming certain imbalances of chemicals of neurotransmitters in the regions of our brain. The antidepressants are used in the medication several cases which not only include depression but some anxiety disorder, nervousness, obsessive-compulsive disorder, manic-depressive disorders, major depressive disorder, diabetic peripheral neuropathic pain, and posttraumatic stress disorder [10]. One of the first drugs used in the treatment of depression is benzodiazepines but they have unwanted effects such as the relaxation of muscle, a sedating effect, addiction, and drug interaction [11].

The genus Gaultheria (Ericaceae) is widely distributed around the Pacific Ocean, westwards to western slopes of the Himalayas, and the southern areas of India. Modern research has demonstrated that these plants exhibit anti-inflammatory, antioxidative, antibacterial, and analgesic activities. The occurrence of Gaultheria fragrantissima in Nilgiris, Travancores, and Toungoo hills in Burma, Ceylon, and Nepal to Bhutan at an altitude of 6,000-8,000 ft. Assam and also in Khasi hills, Meghalaya and the Western Ghats are being reported [12].

There are 19 flavonoids, 10 lignans, and seven simple phenylpropanoids, steroids, and terpenoids in the genus Gaultheria. From the aerial parts of G. yunnanensis it displays significant analgesic and antiinflammatory activities, which has impelled several studies on the 
phytochemistry and biology of the genus Gaultheria [13]. In the present study, G. fragrantissima Wall. has been selected as it is locally used as a medicinal plant. However, scientific data regarding the use of G. fragrantissima Wall. for analgesic and antidepressant activity are not available for plant leaves. Hence, the present study has been chosen to evaluate the in vivo analgesic and antidepressant activity.

\section{METHODS}

Collection of plant and authentication

The leaves of $G$. fragrantissima Wall. were collected in February 2019 from Mawsawa, Mylliem Village, East Khasi Hills, Meghalaya. The plant was taxonomically identified and authenticated by Botanical Survey of India (BSI), Shillong. The identification number given was No. BSI/ERC/ Tech/ 2019-20/26.

\section{Chemical and reagents}

The standard drug diclofenac was obtained from Merck. All the other chemicals were analytical standard.

\section{Preparation of the extract}

The collected plants were dried under shade and the dried leaves were pulverized to get a powder leaves and were extracted by Soxhlet apparatus with petroleum ether followed by chloroform then $95 \%$ methanol. The extraction was carried out exhaustively and the solvents were recovered. The concentrated extracts were kept in the refrigerator at $4^{\circ} \mathrm{C}$ for further use.

\section{Phytochemical screening}

Phytochemical screening of the methanol extract of G. fragrantissima Wall. was carried out by employing standard procedures and tests to detect the presence or absence of chemical constituents such as glycosides, saponins, alkaloids, triterpenoids, carbohydrates, protein and amino acids, steroids, tannins, phenolics, volatile oil, flavonoids, and pectins [14].

\section{Animal care and handling}

Both male and female Wistar rats (150-200 g) used in the study were obtained from the inbred colony and are acclimatized at least for 7 days at the Animal House Facility of Department of Pharmacy, Regional Institute of Paramedical and Nursing Sciences, Mizoram, India. Animals were kept under standard laboratory condition, that is, temperature $\left(25 \pm 2^{\circ} \mathrm{C}\right)$, humidity $(55-60 \%)$, and $12 \mathrm{~h}$ light and dark cycles were maintained. Animals were allowed to free access to food and water. All animal experiments were carried out according to NIH, USA, and Indian National Science Academy, New Delhi, India, guidelines. Before the experiment, the Institutional Animal Ethics Committees approval was taken with the reference no. IAEC/RIPANS/56.

\section{Acute toxicity studies}

Acute oral toxicity was performed as per OECD guideline 425 . Two groups of animals were used for the study. Group I served as control and received distilled water. Group II received a single oral dose of $G$. fragrantissima $(2000 \mathrm{mg} / \mathrm{kg})$. The animals were observed for gross behavioral, neurological, autonomic, and toxic effects at short intervals of time for 24 $\mathrm{h}$ and then daily for 14 days for any sign of delayed toxicity [15].

\section{In vivo analgesic methods}

Hot plate method

This test consists of introducing a rat into an open-ended cylindrical space with a floor consisting of a metallic plate which is heated at a constant temperature. This produces two behavioral components, which are measured in terms of their reaction times, namely, paw licking and jumping. These responses are considered to be supraspinally integrated. Rats of either sex were divided into four groups, each consisting of five animals.

All animals fasted overnight. Two groups were given different doses of the plant extract (determined based on acute toxicity, p.o.), while one group was given a vehicle (control, p.o.) and diclofenac sodium (100 mg/ $\mathrm{kg}$ ) was used, respectively, as standard [16,17]. Then, $1 \mathrm{~h}$ after the orally administration, rats were placed onto a hot plate $\left(55 \pm 2^{\circ} \mathrm{C}\right)$, and the reaction time for licking of paw or jumping for the control and treated mice was recorded (in seconds). Before the treatment, the reaction time of each animal was recorded. The latency to lick the paw or jump from the hot plate was noted as the reaction time. The reaction times were noted at $30,60,90,120$, and $180 \mathrm{~min}$. The cutoff time was considered as $15 \mathrm{~s}$ [18].

\section{Tail immersion test}

A tail immersion test was used to assess the analgesic activity of G. fragrantissima. In this method, five rats per group were used. Tail immersion method involved immersing the extreme $3 \mathrm{~cm}$ of the rat's tail in a glass beaker containing water at a temperature of $55.0 \pm 0.5^{\circ} \mathrm{C}$. After immersing within a few minutes, the rat reacted by withdrawing the tail. The reaction time was noted on a stopwatch. The test groups were given a methanolic extract of $G$. fragrantissima $(400 \mathrm{mg} / \mathrm{kg}$ and $200 \mathrm{mg} / \mathrm{kg}$, p.o.) and diclofenac sodium (100 mg/kg p.o) was used, respectively, as standard and $1 \mathrm{ml} / \mathrm{kg}$ saline solution for the control group (p.o.). The reaction time of the test groups was taken at 30, 60, 90,120 , and $180 \mathrm{~min}$ after a latency period of $30 \mathrm{~min}$ following the administration of the tests substances. The cutoff time, that is, time of no response was put at $12 \mathrm{~s}$. The reaction time was measured and calculated [19].

\section{In vivo antidepressant}

Force swimming test

The method used was similar to that described by Porsolt et al., animals were randomly divided into four groups. Thirty minutes after treatment with the methanol extract of $G$. fragrantissima and imipramine (a reference) antidepressant drug, control is normal saline. Rats were individually placed in an open cylindrical container $(35 \mathrm{~cm}$ height $\times 24$ $\mathrm{cm}$ diameter) containing $13.5 \mathrm{~cm}$ of water at $22-25^{\circ} \mathrm{C}$ for $6 \mathrm{~min}$. The duration of immobility was scored during the past $4 \mathrm{~min}$ of the $6 \mathrm{~min}$ test period. Rats were recorded as immobile when floating motionless or making only those movements necessary to keep the head above water. A decrease in the duration of immobility during the forced swimming test was taken as a measure of antidepressant activity [20].

\section{Tail suspension test (TST)}

The total duration of immobility induced by tail suspension was measured according to the method of Steru et al. Animals were randomly divided into four groups. Thirty minutes after treatment with the methanol extract of $G$. fragrantissima and imipramine (a reference) antidepressant drug, control is normal saline. Rats were suspended $50 \mathrm{~cm}$ above the floor by adhesive tape placed approximately $1 \mathrm{~cm}$ from the tip of the tail. Immobility time was recorded during a 6 min test. A decrease in the duration of immobility during the forced swimming test was taken as a measure of antidepressant activity [21]

\section{Statistical analysis}

All values were shown as Mean \pm SEM $(n=4)$. Statistical analysis was performed using one-way analysis of variance (ANOVA) followed by Tukey-Kramer multiple test. $\mathrm{p}<0.05$ was considered statistically significant. ${ }^{*} \mathrm{p}<0.05$ and ${ }^{* *} \mathrm{p}<0.01$ when compared with control. All analyses were made with the statistical software GraphPad InStat.

\section{RESULTS}

Result of phytochemical screening

Table 1 shows the results of the phytochemical screening of the methanolic extract of $G$. fragrantissima.

The tests identify the presence of phenols and tannins, flavonoid, steroid and triterpenoid, saponin, carbohydrates, volatile oil, and pectin in methanol extract of $G$. fragrantissima.

\section{Acute toxicity test}

Since extract of the plant was already used as traditional medicine and there was no sign of toxicity from its consumption, an acute toxicity test 
was performed according to the limit test of OECD 425 guidelines. It was found that at the dose of $2000 \mathrm{mg} / \mathrm{kg}$ body weight did not produce any mortality to the subjected test animal (female albino rats). The animals were observed for 14 days after dosing and no clinical and behavioral changes were observed during this period.

\section{In vivo analgesic activity}

Hot plate method

The results of the analgesic activity of the methanolic extract of $G$. fragrantissima extract using the hot plate method are presented in Fig. 1.

There was no significant difference in the thermal stimulus in mice treated with the vehicle (control) throughout the whole time of the experiment. Diclofenac administration significantly increased the response time of the animal to reach $7.83 \pm 0.390$ (at $120 \mathrm{~min}$ ) and is considered as extremely significant when compared to the control group $(\mathrm{p}<0.001)$. All doses of $G$. fragrantissima extract showed a significant increase in the latency time of mice when compared to the control group. As shown in Fig. 1, the maximum activities were obtained after $2 \mathrm{~h}$ with $7.114 \pm 0.469$ and $7.538 \pm 0.070 \mathrm{~s}$ for 200 and $400 \mathrm{mg} / \mathrm{kg}$ (G. fragrantissima) and are considered as significant when compared to the control group $(p<0.01)$. Fig. 1 demonstrates the relative activity of G. fragrantissima with respect to the standard drug (diclofenac) in the hot plate method. The analgesic activity in the standard and extracts treated in animals is noted from $30 \mathrm{~min}$ onward till $180 \mathrm{~min}$ in which response peaked at $120 \mathrm{~min}$ for diclofenac sodium and at $120 \mathrm{~min}$ for both the extracts at low and high dose. The result shows us that when in comparison, the high dose is almost equivalently potent to the standard diclofenac sodium, though standard is more potent than the low dose.

Table 1: Results of preliminary phytochemical tests

\begin{tabular}{lll}
\hline S. No. & Phytochemical tests & Methanol extract \\
\hline 1. & Alkaloids & - \\
2. & Glycosides & - \\
3. & Phenols and tannins & + \\
4. & Flavonoids & + \\
5. & Steroids and triterpenoids & + \\
6. & Saponins & + \\
7. & Carbohydrates & + \\
8. & Protein and amino acid & - \\
9. & Fats and fixed oils & - \\
10. & Volatile oil & + \\
11. & Pectin & + \\
\hline
\end{tabular}

$(+)$ indicates the presence of the tested group, (-) indicates the absence of the tested group

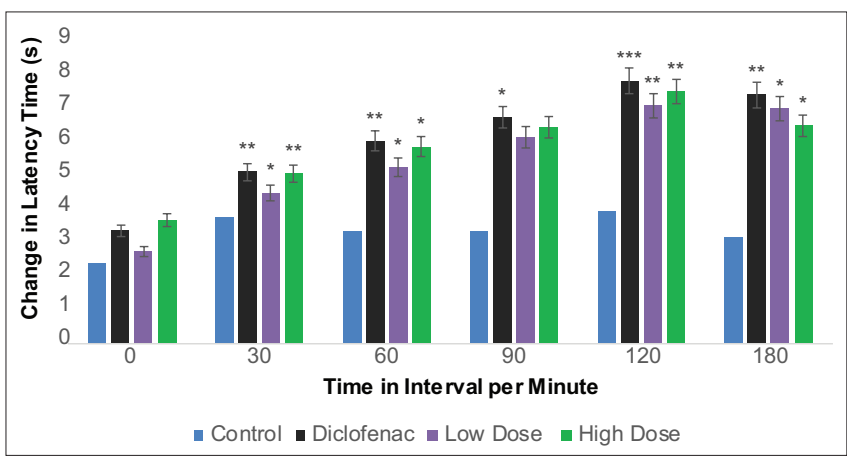

Fig. 1: Analgesic activity of GFE by hot plate method in rats. Values are expressed in Mean $\pm S E M, n=5$. ${ }^{* * *} \mathbf{p}<0.001$ considered extremely significant when compared to the control group. ${ }^{*} \mathbf{p}<0.05$ compared with control, ${ }^{* *} \mathbf{p}<0.01$ compared with control, ${ }^{* * *} \mathbf{p}<0.001$ compared with control. Data were analyzed using one-way ANOVA followed by Tukey-Kramer multiple test
Tail immersion test

The results of the analgesic activity of the methanolic extract of $G$. fragrantissima extract using the tail immersion method are presented in Fig. 2.

There was no significant difference in the thermal stimulus in mice treated with the vehicle (control) throughout the whole time of the experiment. Diclofenac administration significantly increased the response time of the animal to reach $4.902 \pm 0.2595 \mathrm{~s}$ (at $90 \mathrm{~min}$ ) and is considered as extremely significant when compared to control group $(\mathrm{p}<0.001)$. All doses of $G$. fragrantissima extract showed a significant increase in the latency time of rats when compared to the control group. As shown in Fig. 2, the maximum activities were obtained after 90 min with $4.01 \pm 0.222$ and $2.704 \pm 0.2515 \mathrm{~s}$ for 400 and $200 \mathrm{mg} / \mathrm{kg}$ (G. fragrantissima) and are considered as significant when compared to the control group $(\mathrm{p}<0.01)$. Fig. 2 demonstrates the relative activity of $G$. fragrantissima extract with respect to the standard drug (diclofenac sodium) in the tail immersion method. The analgesic activity in the standard and extracts treated in animals is noted from $30 \mathrm{~min}$ onward till $120 \mathrm{~min}$ in which response peaked at $90 \mathrm{~min}$ for diclofenac sodium and at $90 \mathrm{~min}$ for both the extracts at low and high dose. The result shows us that when in comparison, the high dose is almost equivalently potent to the standard diclofenac sodium, though the standard is more potent than the low dose.

Findings from Figs. 1 and 2 demonstrate that the methanol extract at the dose of $400 \mathrm{mg} / \mathrm{kg}$ prolonged the reaction time in the hot plate method and the tail immersion method. Taken together sensitivity of both methods as well as the mechanism involved may explain the analgesic effects observed in this study.

\section{In vivo antidepressant activity}

The antidepressant effect of the methanolic extract of G. fragrantissima $(200$ and $400 \mathrm{mg} / \mathrm{kg}$ ) and imipramine was studied by observing the changes in the duration of immobility in the two models: Forced swim test (FST) and TST. These tests are used to monitor depressive-like behavior and are based on the assumption that immobility reflects a measure of behavioral despair. The methanol extract of $G$. fragrantissima $(200$ and $400 \mathrm{mg} / \mathrm{kg}$ ) produced a significant reduction $(\mathrm{p}<0.001)$ in the immobility period when compared with that of control group animals. The immobility time in sec of the high dose of $G$. fragrantissima is $143.2 \pm 1.985$ as compared to the control which is $185 \pm 3.661$ in FST. The immobility time in sec of the high dose of G. fragrantissima is $100.8 \pm 7.116$ as compared to the control which is $202.2 \pm 4.247$ in the TST as seen in the results tabulated in Figs. 3 and 4

\section{DISCUSSION}

After performing the acute toxicity studies, it was found that at the dose of $2000 \mathrm{mg} / \mathrm{kg}$ body weight did not produce any mortality to the

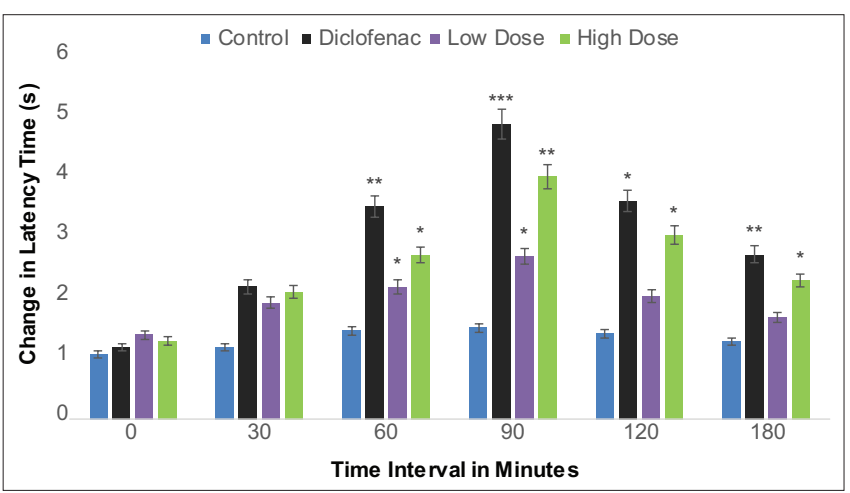

Fig. 2: Analgesic activity of GFE by tail immersion in rats. Values are expressed in Mean $\pm \mathrm{SEM}, \mathrm{n}=5 . * * * \mathrm{p}<0.001$ considered extremely significant when compared to control group. ${ }^{*} \mathrm{p}<0.05$ compared with control, $* * \mathbf{p}<0.01$ compared with control,

$* * * \mathbf{p}<0.001$ compared with the control. Data were analyzed using one-way ANOVA followed by Tukey-Kramer multiple test. 


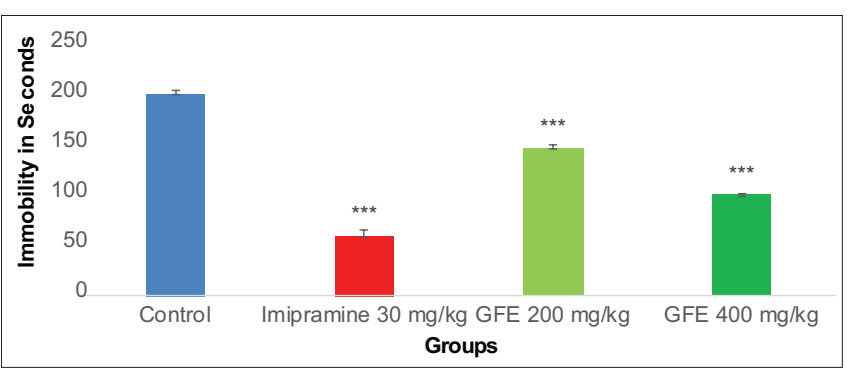

Fig. 3: Antidepressant activity of GFE by forced swim test. Values are expressed in Mean $\pm \mathrm{SEM}, \mathbf{n}=5$. ${ }^{* * *} \mathbf{p}<0.001$ considered extremely significant when compared to control group. ${ }^{*} \mathbf{p}<0.05$ compared with control, ${ }^{* *} \mathrm{p}<0.01$ compared with control, $* * * \mathbf{p}<0.001$ compared with the control. Data were analyzed using one-way ANOVA followed by Tukey-Kramer multiple test.

subjected test animal (female albino rats). The animals were observed for 14 days after dosing, and no clinical and behavioral changes were observed during this period. Hence, the $\mathrm{LD}_{50}$ of $G$. fragrantissima extract was more than $2000 \mathrm{mg} / \mathrm{kg}$ body weight and was safe for further use.

Results from the analgesic activity studies reveal that the methanol extract of the leaf of $G$. fragrantissima acts as an analgesic agent.

Analgesics are drugs that act on the central or peripheral nervous system to relieve pain selectively without altering consciousness. Centrally acting analgesics act by increasing the threshold for pain and altering the physiological response to pain. However, peripherally acting drugs act by inhibiting the generation of pain impulses at the chemoreceptor level [22].

It also revealed that the plant possesses significant analgesic activities as the presence of flavonoids, tannins were confirmed. Flavonoids were reported to have a role in an analgesic activity primarily by targeting PGs $[23,24]$. There are also reports on the role of tannins in anti-nociceptive activity [25]. The methanolic extracts of the plants in NSAIDs inhibit peripheral pain [26].

The analgesic effect of the plants in both models suggests that they have been acting through a peripheral mechanism. The analgesic activity may be due to its ability to inactivate the pain receptors at the receptor site level. It may also inhibit endogenous pain substances, which are involved in the peripheral analgesia.

The methanol extract of $G$. fragrantissima (200 and $400 \mathrm{mg} / \mathrm{kg}$ ) produced a significant reduction $(\mathrm{p}<0.001)$ in the immobility period when compared with that of control group animals that received only the vehicle in both the FST and TST.

Forced swimming and TSTs which represent the behavioral despair model claimed to reproduce a condition similar to human depression [27]. The tests are based on the observation that animals, following initial escape oriented movements, develop an immobile posture when placed in an inescapable chamber. The immobility is thought to reflect either a failure of persistence in escape-directed behavior (i.e., behavioral despair) or the development of passive behavior that disengages the animal from active forms of coping with stressful stimuli [28].

It is well known that clinically effective antidepressants (such as imipramine) typically increase the swimming efforts of the animal seeking a solution to the problem and, therefore, decrease the duration of immobility in the forced swimming test and this was observed in this study. Phytochemical analysis showed that the presence of flavonoids and phenolic compounds has been reported to have multiple biological effects such as central nervous system disorders [29].

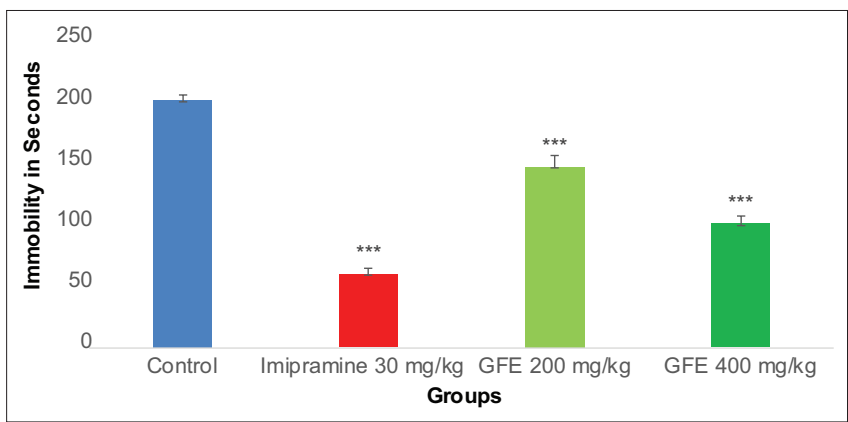

Fig. 4: Antidepressant activity of GFE by tail suspension. Values are expressed in Mean $\pm \mathrm{SEM}, \mathrm{n}=5$. $* * * \mathrm{p}<0.001$ considered extremely significant when compared to control group. * $\mathbf{p}<0.05$ compared with control, ${ }^{* *} \mathbf{p}<0.01$ compared with control, ${ }^{* * *} \mathbf{p}<0.001$ compared with the control. Data were analyzed using one-way ANOVA followed by Tukey-Kramer multiple test

G. fragrantissima Wall. in this study has been proven that it possesses antidepressant properties through the two test models which makes the hypothesis plausible. The data collected make this study significant as it leads to the possibility of exploiting new resources that are in abundance and providing an alternative to the current availability of antidepressant drugs.

The findings in this study might help in the verdicts of new lead compounds in the field of analgesic and antidepressant drug research after the widespread investigation on bioactivity, mechanism of action, pharmacotherapeutics, toxicity, and after proper standardization and clinical trials.

\section{CONCLUSION}

All the phytochemical screening and the pharmacological experiments carried out with the methanolic extract of $G$. fragrantissima Wall. suggest to us that it possesses analgesic activities and the result from antidepressant activity study indicates that the methanol extract of the leaf of $G$. fragrantissima possesses antidepressant activities.

Further investigation is, however, required to find out the active compound(s), mechanism of action, and effective dose before administration in human and veterinary use.

\section{ACKNOWLEDGEMENT}

The authors acknowledge their sincere gratitude to the director of RIPANS, Aizawl, India, for providing us with the necessary facilities to carry out this research work.

\section{AUTHORS' CONTRIBUTIONS}

All the authors have contributed equally to this research work.

\section{CONFLICTS OF INTEREST}

There were no conflicts of interest or financial support among the authors.

\section{AUTHORS' FUNDING}

The experiment was funded by the Department of Pharmacy, RIPANS, Aizawl.

\section{REFERENCES}

1. Abdullahi AA. Trends and challenges of traditional medicine in Africa. Afr J Tradit Complement Altern Med 2011;8:115-23.

2. Gurib-Fakim A. Medicinal plants: Traditions of yesterday and drugs of tomorrow. Mol Aspects Med 2006;27:1-93.

3. Qi FH, Wang ZX, Cai PP, Zhao L, Gao JJ, Kokudo N, et al. Traditional 
Chinese medicine and related active compounds: A review of their role on hepatitis B virus infection. Drug Discov Ther 2013;7:212-24.

4. Yuan H, Ma Q, Piao G. The traditional medicine and modern medicine from natural products. Molecules 2016;21:559.

5. Johan, Instiaty, Nafrialdi, Purwosunu Y. A prospective survey of appropriateness of pain pharmacotherapy management in post-cesarean section patients in Cipto Mangunkusumo Hospital. Int J Appl Pharm 2019;11:280-3

6. Londhey VA. Pathophysiology of pain. J Assoc Physicians India 2015;63:5-7.

7. Rang HP, Dale MM, Ritter JM, Flower RJ, Henderson G. Rang and Dale's Pharmacology. $7^{\text {th }}$ ed. Philadelphia, PA: Churchill Livingstone Publisher; 2012. p. 228-9.

8. Sutar NG, Pal SC. Evalution of analgesic activity of leaf extracts of pergularia daemia [forsk] in experimental animals. Int J Pharm Pharm Sci 2014;6:137-9.

9. Santosh P, Venugopl R, Nilakash AS, Kunjbihari S, Mangala L. Antidepressant activity of methanolic extract of Passiflora foetida leaves in mice. Int J Pharm Pharm Sci 2011;3:112-5.

10. Khushboo, Sharma B. Antidepressants: Mechanism of action, toxicity and possible amelioration. J Appl Biotechnol Bioeng 2017;3:437-48.

11. Pamulaparthi A, Prathap VR, Banala M, Nanna RS. Experimental evaluation of antidepressant and antianxiety activities of aqueous leaf extracts of Senna alata (L.) Roxb. Using in vitro animal models. Int J Curr Pharm Res 2016;8:60-3.

12. Ranyaphi RA. Literature Review on Gaultheria fragrantissima Wall. Studies on Propagation and Essential Oil Content in Gaultheria fragrantissma Wall. Doctoral Dissertation. Guwahati, Assam: Gauhati University; 2011. p. 11-3.

13. Liu WR, Qiao WL, Liu Z, Wang XH, Jiang R, Li SY, et al. Gaultheria: Phytochemical and pharmacological characteristics. Molecules 2013;18:12071-108.

14. Kokate CK, Purohit AP, Gokhale SB. Textbook of Pharmacognosy. Pune: Nirali Prakashan Publisher; 2012. p. 12.3-12.6.

15. Organisation for Economic Co-operation and Development. Test No. 425: Acute Oral Toxicity: Up-and-Down Procedure, OECD Guidelines for the Testing of Chemicals. Paris: Organisation for Economic Cooperation and Development Publishing; 2008. p. 4.

16. Ojewole JO. Antiinflammatory and analgesic effects of Psidium guajava Linn. (Myrtaceae) leaf aqueous extract in rats and mice.
Methods Find Exp Clin Pharmacol 2006;28:441-6.

17. Hijazi MA, El-Mallah A, Aboul-Ela M, Ellakany A. Evaluation of analgesic activity of Papaver libanoticum extract in mice: Involvement of opioids receptors. Evid Based Complement Altern Med 2017;2017:8935085.

18. Neto AG, Costa JM, Belati CC, Vinhólis AH. Analgesic and antiinflammatory activity of a crude root extract of Pfaffia glomerata (Spreng) pedersen. J Ethnopharmacol 2005;96:87-91.

19. Suseem SR, Mary Saral A, Neelakanda Reddy P, Marslin G. Evaluation of the analgesic activity of ethyl acetate, methanol and aqueous extracts of Pleurotus eous mushroom. Asia Pac J Trop Med 2011;4:117-20.

20. Porsolt RD, Anton G, Blavet N, Jalfre M. Behavioural despair in rats: A new model sensitive to antidepressant treatments. Eur J Pharmacol 1978;47:379-91.

21. Steru L, Chermat R, Thierry B, Simon P. The tail suspension test: A new method for screening antidepressants in mice. Psychopharmacology (Berl) $1985 ; 85: 367-70$

22. Shreedhara CS, Vaidya VP, Vagdevi HM, Latha KP, Muralikrishna KS, Krupanidhi AM. Screening of Bauhinia purpurea Linn. For analgesic and anti-inflammatory activities. Indian J Pharmacol 2009;41:75-9.

23. Narayana KR, Reddy MS, Chaluvadi MR, Krishna DR. Bioflavonoids classification, pharmacological, biochemical effects and therapeutic potential. Indian J Pharmacol 2001;33:2-16.

24. Ramesh M, Rao YM, Rao AV, Prabhakar MC, Rao CS, Muralidhar N. Antinociceptive and anti-inflammatory activity of a flavonoid isolated from Caralluma attenuata. J Ethnopharmacol 1998;62:63-6.

25. Ramprasath VR, Shanthi P, Sachdanandam P. Immunomodulatory and anti-inflammatory effects of Semecarpus anacardium LINN. Nut milk extract in experimental inflammatory conditions. Biol Pharm Bull 2006;29:693-700.

26. Elisabetsky E, Amador TA, Albuquerque RR, Nunes DS, Carvalho Ado C. Analgesic activity of Psychotria colorata (Willd. ex R. \& S.) Muell. Arg. alkaloids. J Ethnopharmacol 1995;48:77-83.

27. Willner P. The validity of animal models of depression. Psychopharmacology (Berl) 1984;83:1-16.

28. Lucki I. The forced swimming test as a model for core and component behavioral effects of antidepressant drugs. Behav Pharmacol 1997;8:523-32.

29. Priyanka B, Sridhar Y, Shankaraiah P. Antidepressant and muscle relaxant activity of Cardiospermum halicacabum Linn. Roots in mice. J Adv Pharm Sci 2012;2:193-200. 